\title{
Smart Guide Stick for Blind People Using Artificial Intelligence
}

\author{
Divya Rathore, Damini Harde, Pratiksha Nagrare, Mona , Komal Madarkar \\ Prof. Dr. (Mrs.) A. V. Dehankar \\ Department of Computer Technology \\ Priyadarshini College of Engineering, Nagpur, India, 440016
}

\begin{abstract}
Blindness is a condition in which a person is unable to see and detect the things happening in his/her surroundings that cause various problems, which cannot be solved by medical means. The difficult situations arise in front of blind person when he/she is travelling in his/her path. He/she is unable to determine obstacles appearing in front of them. Therefore, for such reasons, they are unable to move from one place to another. The smart blind stick helps the blind person to find its way during travel and to do their work with ease and in a secure manner. Usually a blind person use conventional stick in which the obstacles are not determined and conventional stick is not that much efficient for blind person. The conventional blind stick is unable to recognize and detect what type of things or objects is coming in front of him/her. The quick progress in technology has brought the re-structuring of better system for assisting the differently abled, including the blind, such as AI image processing, which can provide intelligent navigation capabilities to the blind. This paper reviews the design of the smart guide stick having A.I. technologies such as object detection and image processing which helps the blind person to travel in his/her path easily.
\end{abstract}

Keywords- feature extraction, filtering, image processing

\section{I-LITERATURE REVIEW}

$\mathbf{T}$ he vision, construct a mental representation of the world around us. This contribute to our ability to successfully navigate through physical space and interact with important individuals and objects in our environments. Eye is the most significant part of our human body. Most of the environmental information is obtained to a person is through, his/her sight.
Although, there are many people with severe vision impairment that prevent them from travelling individually over their path. According to a 2010 report by the World Health Organization (WHO) there are people of all ages who are visually impaired and their number estimated is 285 million of whom 39 millon are blind. People 50 years and older are $82 \%$ of all blind. Consistently, these blind persons must use range of proficiency and tools which will help them in travelling in their path.

Some of the oldest tools for the blind person have been the walking stick also known as the wide stick, though useful these aids have significant problems. The rapid growth of modern technology has, although saw the arrival of better system such as the assisted vision smart glasses and smart guide stick that can provide intelligent navigation capability to the blind person. This paper reviews the design of a guide stick, i.e. an Artificial Intelligence based smart guide stick, furnished with image recognition and image processing technologies that takeover front-side, and backend images and use Artificial Intelligence and machine learning to operate them.

The main aim of the smart guide stick is to detect obstacles and to inform the blind person previously the objects coming in front of him/her. The obstacles or the objects coming in front of the blind person is given in the form of audio messages to the blind person which will make them attentive and thus reduce the chances of accidents. A voice messages enable automatic switching is also included to help them in their private space. The smart guide stick will detect the images of obstacles which are present in outdoor and indoor with the help of camera.

The smart Guide Stick is a simple and purely automatic device to determine the obstacles in the path. This device is light-weight and can be easily 
portable. But it has a limited range due to its own size. It provides the best travel aid for the person. The blind person can move from one place to another independently without others help. The main goal of the system is to provide an efficient navigation means for the blind persons which gives an eyesight by providing the information about objects present in their surroundings.

AI based smart guide stick is an innovative stick which will help in making smart decisions about the selection of path that has no obstacles till a certain distance. Our blind stick involve predefined commands for a blind person by using image processing technique from camera and sensors front, left and right that will provide the blind person the predefined message in order to move over their path. The camera senses the obstacles and processes the image and directs the blind person with a specified message to move in a particular direction. The message will be given in the form of voice via headphones. This helps blind person in walking.

\section{II-SYSTEM DESIGN}

System design is the process of defining the elements of a system such as the architecture, module and components, the different interfaces of those component and the data that goes through that system. The system can be broadly classified into the input unit, the control unit and the output unit. This units are aligned on the blind stick for the perfect object and the edge detection. The stick is embedded with Sensors, Arduino Nano, Batteries, Buzzer, Bluetooth, and Camera.

If the visually impaired person is walking with his/her stick into his/her hand they will be knowing the obstacles coming in front of them through the camera which will do the image processing of the obstacles coming before its path.

The sensors like Ultrasonic sensor HC-SR04 are placed over the blind stick which makes it robust.

If the stick of the visually impaired person has been dropped then the buzzer will is going to buzz.

If the blind person is moving in a particular direction and in a certain path, the obstacles coming in the path of the blind person are being recognised by the camera and the audio message will be given to the blind person via Bluetooth. The stick is made artificially intelligent by image processing technique and feature extracting method.

\subsection{Block Diagram:}

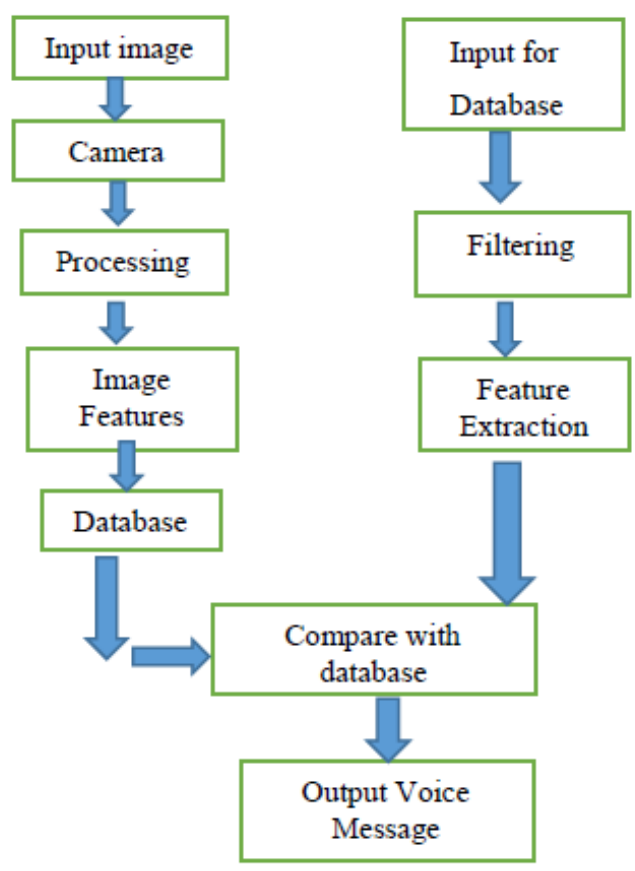

Fig. 1- Block Diagram

\subsection{Camera:}

A web cam is a small digital video camera directly or indirectly connected to a computer or a computer network. Webcams are having the software that will be installed in the computer to help the blind person to record image of the obstacles coming in the path of him/her. The clustering algorithm is used for image detection which will take the image of the obstacles as input. These input are compared with images stored in database in order to identify them. The MATLAB is coded in $\mathrm{C}$ language to get the number of images recognised by the camera in the text format. The output is given after converting the text i.e. code in the form of voice message.

\subsection{Ultrasonic Sensor HC-SR04}

The HC-SR04 ultrasonic distance sensor is a sensor used for detecting the distance to an object using sonar. The transmitters emit a high frequency ultrasonic sound, which bounce off any solid objects, and the receiver listen for any return echo. The HCSR04 ultrasonic sensor in the smart guide stick will judge the distance of the obstacle by the time taken by the ultrasonic signal to strike the obstacle and return. The ultrasonic sensor is connected with arduino. The 
output of these sensor is connected by a buzzer. Arduino can be coded according to the requirements.

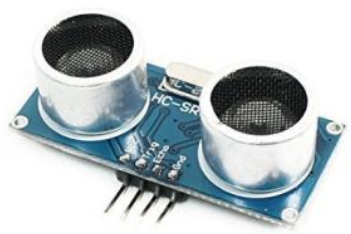

Fig. 2 : Ultrasonic Sensor

\subsection{Battery}

A Battery is used for providing the electrical power to the smart guide stick. 9volt battery is used in the smart guide stick to provide processing of the equipment attached over the smart guide stick.

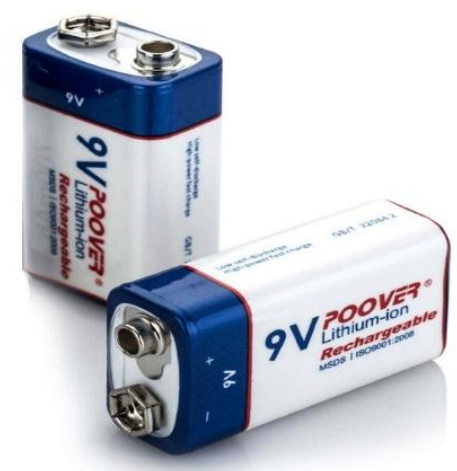

Fig. 3 : Battery

\subsection{Buzzer}

Buzzer is an audio signalling device, which may be mechanical or electromechanical. The buzzer on the smart guide stick is used to indicate the blind person about the position of the bling stick when it is dropped. This will help the blind person to find his/her blind stick without any problems.

\subsection{Arduino Nano}

The Arduino Nano is a small, complete, and breadboard-friendly board based on the AT Mega 328P i.e. Arduino Nano 3.8. The Ultrasonic Sensors are connected with the Arduino and the output is given further.

\subsection{Bluetooth}

Bluetooth is a wireless technology standard used for exchanging data between fixed and moving device over short distances. The Bluetooth is connected to the smart guide stick to provide information in the form of audio message of the obstacles coming in the path of blind person.

\section{A. Image Processing}

Image processing to remove noise from the image or other object removal, different processing unit. Here, we are using K-clustering algorithm which will help in image processing and manipulate the image to transform according to the shape and size.

\section{B. Feature Extraction:}

SFeature Extraction is an important part in the identification of the obstacles coming in the path of the blind person. Feature extraction is used in many applications in image processing. Colour, texture, edges are the features which are used in image detection.

In feature extraction here we are using K-clustering algorithm, which first extract the feature of image and after the whole implementation of process it transforms the image.

\section{K- Means Clustering Algorithm}

K-Means Clustering is a type of unsupervised learning, which is used when you have data without defined categories or groups. The goal of this algorithm is to find groups and the data, with the number of groups represented by the variable $\mathrm{k}$. The algorithm works iteratively to provide each data point to one of $\mathrm{k}$ groups based on the features that are provided. Data points are cluster based on feature similarity. The k clustering algorithms are:

1. The centroid of the $\mathrm{k}$ cluster, which can be used to label new data.

2. Each data point is labels for the each data point is assigned to a single cluster.

\section{Advantages:}

- Obstacles detection with indication support.

- Speech matching which helps blind and physical disable to recognise the destination.

- Alert blind people about dig coming in front of them.

Fig. 4 : Arduino Nano
- Simple to use and low cost, 


\section{III- CONCLUSION}

The assistive device for blind people has been designed focusing upon the ease of travelling for the blind people. The project put forward the design and contruction of a new concept of smart Artificial Intellegence based guide stick for blind person. The advantage of the smart blind stick rest on the fact that it can validate to be very low cost solution to millions of blind persons across the world.The advance combination of various working units makes a realtime system that makes travelling of a blind person more safe and secure. The smart guide stick helps the blind people when the obstacle occurs in front of the person. The stick gives signal to the person by buzzer sound when it detects the obstacle. It can be further improved to have more decision taking capabilities by employing varied types of sensors and thus could be used for different applications. The main motive of the smart blind stick is to solve the various problems and difficulties faced by the blind people during travelling to their path and to make their life easier.

\section{REFERENCES}

[1] Borenstein, Johann \& Iwan Ulrich. "The GuideCane-A Computerized Travel Aid for the Active Guidance of Blind Pedestrians." Proceedings of the IEEE International Conference on Robotics \& Automation, Albuquerque, NM, 21-27 April 1997, pp. 1283-1288.

[2] Dhanuja, R., F. Farhana, \& G. Savitha. "Smart Blind Stick Using Arduino." International Research Journal of Engineering and Technology, vol. 5, no. 3, 2008, pp. 2553-2555.

[3] Elmannai, Wafa \& Khaled Elleithy. "Sensor-Based Assistive Devices for Visually-Impaired People: Current Status, Challenges, and Future Directions." Sensors (Basel), vol. 17, no. 3, 2017, pp. 565.

[4] Jose, Jacio, Miguel Farrajota, Joae Rodrigues, and Hans du Baf. "The Smart Vision Local Navigation Aid for the Blind and Visually Impaired Persons." International Journal if Digital Content Technology, vol. 5, 2011, pp. 1

[5] Koley, Somnath \& Ravi Mishra. "Voice Operated Outdoor Navigation System for Visually Impaired Persons." International Journal of Engineering Trends and Technology, vol. 3, no. 2, 2012, pp. 153-157. Kumbhare, Shruti \& A. Sakhore. "A Smart Stick for Blind Obstacle Detection, Artificial Vision and Real Time Assistance via GPS." International Journal of Computers, vol. 7, 2011.

[6] Nada, Ayat, Samia Mashelly, Mahmoud A. Fakhr, and Ahmed F. Seddik. "Effective Fast Response Smart Stick for Blind People." Second International Conference on Advances in Bio-Informatics and Environmental Engineering - ICABEE, At Italy, 2015.

[7] Pissaloux, Edwige and Ramiro Velazquez (Eds.). Mobility of Visually Impaired People: Fundamentals and ICT Assistive Technologies. New York, NY: Springer, 2018.

[8] Rutkowski, Leszek, Marcin Korytkowski, Rafal Scherer, Ryszard Tadeusiewicz, Lotfi A. Zadeh, and Jacek M. Zurada. "Artificial Intelligence and Soft Computing." 